\title{
Sea-level databases
}

Nicole S. Khan', F. Hibbert ${ }^{2}$ and A. Rovere ${ }^{3}$

The study of past sea levels relies on the availability of standardized sea-level reconstructions, which allow for broad comparison of records from disparate locations to unravel spatial patterns and rates of sea-level change at different timescales. Subsequently, hypotheses about their driving mechanisms can be formulated and tested.

\section{Approach to database compilation} Geological sea-level reconstructions are developed using sea-level proxies, which formed in relation to the past position of sea level and include isotopic, sedimentary, geomorphic, archaeological, and fixed biological indicators, in addition to coral reefs and microatolls, as well as wetland flora and fauna. The past position of sea level over space and time is defined by what are termed sea-level index or limiting points, which are characterized by the following fundamental fields: a) geographic location; b) age of formation, traditionally determined by radiometric methods (e.g. radiocarbon or U-series dating); c) the elevation of the sample with respect to a contemporary tidal datum; and d) the relationship of the proxy to sea level at the time of formation (i.e. the proxy's "indicative meaning", which describes the central tendency (reference water level) and vertical (indicative) range) relative to tidal levels. Although conceptually only four primary fields are necessary to define a sea-level index point, in practice many more fields are required to appropriately archive information related to geological samples (e.g. stratigraphic context, sample collection, laboratory processing), and it is important to distinguish between primary observations and secondary interpretation so that the latter may be updated as science advances (see Hibbert et al. 2016; Hijma et al. 2015).

While this approach was developed through the International Geoscience Programme projects running from the 1970 s to present and has been widely applied to Holocene reconstructions (e.g. Shennan and Horton 2002), it has only more recently been adopted for older archives and time periods (e.g. Rovere et al. 2014, 2016). The standardization of sea-level databases of various ages has been one of the main objectives of the PAGES PALeo constraints on SEA level (PALSEA) working group (Düsterhus et al. 2016) and by projects related to it (e.g. the International Union for Quaternary Research (INQUA) Geographic variability of HOLocene relative SEA level (HOLSEA) and MEDiterranean sea-level change and projection for future FLOODing (MEDFLOOD) projects). Here we describe recent progress and advances in database compilation, and highlight remaining challenges and future directions.

\section{Last Glacial Maximum to present}

The standardization of sea-level databases spanning time periods from the Last Glacial Maximum (LGM) to present has seen rapid development in recent years. Notable progress has been made through a community effort, unified under the HOLSEA project, to develop a standardized global database of post-LGM sea levels. The first iteration of this database was made available in April 2019 through a special issue entitled "Inception of a Global Atlas of Sea Levels since the Last Glacial Maximum" published in Quaternary Science Reviews. Regional contributions in the special issue from Atlantic Canada, the British Isles, the Netherlands, Atlantic Europe, the western Mediterranean, Israel, the Russian Arctic, South Africa, the Malaysian Peninsula, and Southeast Asia, India, Sri Lanka and the Maldives can be combined with recently published regional databases from the Pacific, Gulf, Atlantic, and Caribbean coasts of North America, Atlantic South America, Greenland, Antarctica, northwest Europe, the Barents Sea, the Mediterranean, China, Australia, New Zealand, other low-latitude locations, and high-resolution Common

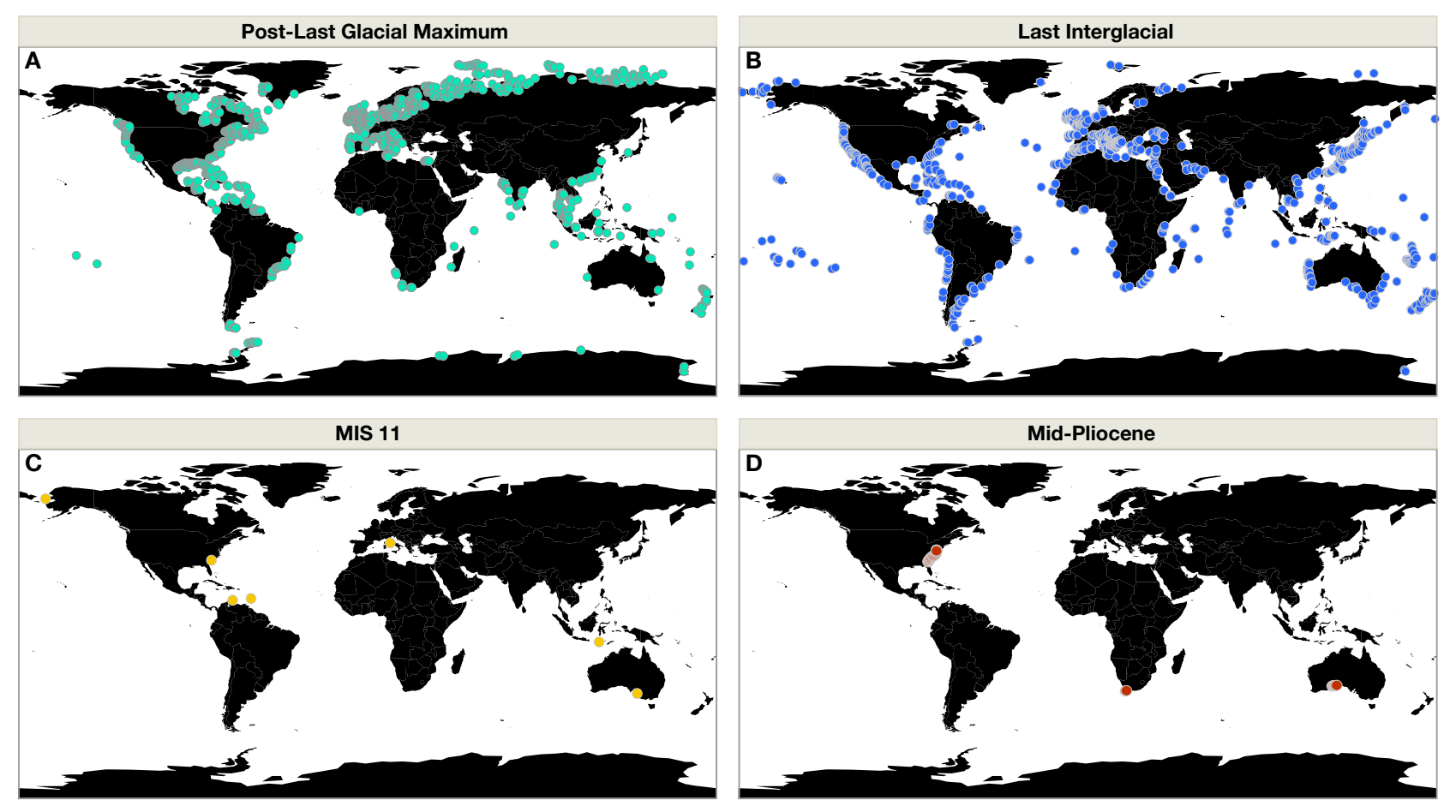

Figure 1: Map showing the spatial distribution of sea-level data from different time periods: (A) the Last Glacial Maximum to present from new regional databases, (B) the Last Interglacial, (C) MIS 11, and (D) the Pliocene. References are given in Box 1. 
Era reconstructions (Kopp et al. 2016; also Barnett et al. this issue; see Fig 1a). However, updates or further standardization may be required to fully integrate these recently published databases. Key spatial gaps remain in Arctic Canada, Pacific Central America, Pacific South America, and African coastlines, and there is a paucity of data spanning the deglacial period (i.e. older than $8 \mathrm{kyr})$.

\section{The Last Interglacial}

For the Last Interglacial, four primary databases collect Marine Isotope Stage (MIS) 5 e sea-level indicators at global scale: 1 ) Kopp et al. (2009) included data from 42 locations and a variety of archives (isotopic, coral reef, geomorphological) and applied a standardized relationship to sea level at the time of formation (i.e. indicative meaning); 2) Pedoja et al. (2014) included data from 942 sites, however only elevation is reported (and often only mean elevations) without consideration of sample indicative meaning; 3) Dutton and Lambeck (2012) concentrated on coral reef archives from 16 sites (710 data points) and crucially standardized the U-series ages; 4) Hibbert et al. (2016) built on the Dutton and Lambeck dataset (32 locations, ca. 2,500 data points, for the last 700 kyr) adding additional standardization and coral depth distributions derived from modern ecological studies (Fig 1b). While at first glance there appears to be an abundance of Last Interglacial data, not all dated sea-level indicators have a full suite of database fields (for example, species dated, elevation, or reliable age determinations). Screening of the available databases suggests there are ca. 500 Last Interglacial sea-level indicators (excluding isotopic archives) with sufficient documentation to allow further analysis, 319 of which are located at 26 different locations on passive margins (Austermann et al. 2017) Databases from older time periods have often been "standalone" efforts with differing objectives, a major drawback of which is the varying way that archives have been interpreted with respect to past sea levels. One way forward is the approach taken by Rovere et al. (2016), where former sea levels are interpreted in terms of the entire geological or sedimentary facies (with ages derived from samples collected from within that facies), rather than considering each individually dated indicator separately.

\section{Plio-Pleistocene interglacials}

Beyond the Last Interglacial, there have been few attempts to compile and standardize sea-level data. Most compilations were completed to support modeling studies that did not focus on the creation of a database per se, and hence standardization is sometimes less rigorous than for Holocene and Last Interglacial proxies. For example, Creveling et al. (2017) report 38 sites dating to MIS $5 a$ and MIS $5 c$ to compare their elevation with glacial isostatic adjustment models. No attempt is made, however, at assessing or standardizing the indicative meaning of each proxy. For older interglacials, Bowen (2010) reported seven sites where MIS 11 shorelines have been preserved (Fig 1c), and Rovere et al. $(2015,2014)$ estimated the indicative meaning for mid-Pliocene shorelines on the Atlantic coasts of the United States, South Africa, and South Australia (Fig 1d).

\section{Future directions}

Progress in improving the standardization of sea-level databases has also been accompanied by advancements in statistical and analytical methods used to infer spatial patterns and rates of RSL change from geological data that have a spatially and temporally sparse distribution and geochronological and elevational uncertainties (e.g. Austermann et al. 2017; Kopp et al. 2009, 2016). Future areas of development include more comprehensive and accurate use of data (e.g. incorporating non-Gaussian data distributions; see Hibbert et al. 2016), integration with physical models and their uncertainties (Milne et al. this issue) using machine learning approaches, and scaling spatio-temporal models to large geological datasets (Ashe et al. 2019).

Challenges remain in integrating databases compiled by different research groups over different time periods, and in developing cyberinfrastructure and open access visualization platforms to improve the longevity and accessibility of databases (e.g. Düsterhus et al. 2016). Improved understanding of the mechanisms driving RSL variability will be achieved through the standardization of sea-level databases, which will enhance the comparability and accessibility of information to improve both physical models and statistical reconstructions.

\section{AFFILIATIONS}

'Asian School of the Environment, Nanyang Technological University, Singapore

${ }^{2}$ Research School of Earth Sciences, Australian National University, Canberra, Australia ${ }^{3}$ MARUM, University of Bremen, Germany

\section{CONTACT}

Nicole Khan: nicolekhan@ntu.edu.sg

\section{REFERENCES}

Ashe EL et al. (2019) Quat Sci Rev 204: 58-77

Austermann J et al. (2017) Sci Adv 3: e1700457

\section{Bowen DQ (2010) Clim Past 6: 19-29}

Creveling JR et al. (2017) Quat Sci Rev 163: 193-208

Düsterhus A et al. (2016) Clim Past 12: 911-921

Dutton A, Lambeck K (2012) Science 337: 216-219

Hibbert FD et al. (2016) Quat Sci Rev 145: 1-56

Hijma M et al. (2015) In: Shennan I et al. (Eds) Handbook

$$
\text { for Sea Level Research. Wiley, 536-553 }
$$

Kopp RE et al. (2009) Nature 462: 863-867

Kopp RE et al. (2016) Proc Natl Acad Sci 113:

$$
\text { E1434-E1441 }
$$

Pedoja K et al. (2014) Earth-Sci Rev 132: 13-38

Rovere A et al. (2014) Earth Planet Sci Lett 387: 27-33

Rovere A et al. (2015) Earth-Sci Rev 145: 117-131

Rovere A et al. (2016) Earth-Sci Rev 159: 404-427

Shennan I, Horton B (2002) J Quat Sci 17: 511-526

\section{Last Glacial Maximum to present}

Long et al. (2011)

Vacchi et al. (2018a)

Baranskaya et al. (2018)

Auriac et al. (2016)

Lambeck et al. (2010)

Briggs and Tarasov (2013)

Shennan et al. (2018)

Hijma and Cohen (2019)

Vink et al. (2007)

García-Artola et al. (2018)

Greenland

Atlantic Canada

Russian Arctic

Barents Sea

Scandinavia

Antarctica

British Isles

northwest Europe

Atlantic Europe

Vacchi et al. $(2014,2016$

2018b)

Shaw et al. (2018)

Dean et al. (2019)

Engelhart and Horton (2012)

Hawkes et al. (2016)

Engelhart et al. (2015)

Reynolds and Simms (2015)

Hijma et al. (2015)

Love et al. (2016)

Khan et al. (2017)

Milne and Peros (2013)

Milne et al. (2005)

Cooper et al. (2019)

Zong (2004)

Mann et al. (2019)

Tam et al. (2018)

Clement et al. (2016)

Lewis et al. (2013)

Hibbert et al. $(2016,2018)$

Mediterranean

US Atlantic

US Pacific

Gulf of Mexico

Circum-Caribbean

Atlantic South America

South Africa

China

Southeast Asia, India

Sri Lanka, and the

Maldives

New Zealand

Australia

Mid to low latitude locations

Khan et al. (2015)

Global

\section{Last Interglacial}

Kopp et al. (2009)

Pedoja et al. (2011, 2014)

Global

Global

Hibbert et al. (2016)

Global

\section{MIS 11}

Bowen et al. (2010)

see Figure 1

\section{Pliocene}

Rovere et al. (2014, 2015) see Figure 1

Box 1: Currently available standardized RSL databases. All data are shown in Figure 1. See online version of this article for links to full references (doi.org/10.22498/pages.27.1.10). 